\title{
Influence of Occlusion Movement on Amount of Parotid Saliva
}

\author{
by \\ Rokuro SUHARA, * Kiyoshi ONO, ${ }^{*}$ Tomio TAKIKAWA* \\ and Masao TANAKA*
}

\section{Introductory}

HAYASHI, ${ }^{1 /}$ HAYAKAWA ${ }^{2)}$ and SUHARA ${ }^{3,5)}$ have made public various results of their researches on the measurement of salivary amounts by the use of a salivary suctioncup that was especially designed for the physical peculiarities of the Japanese people. In the present study, the authors have conducted an inquiry into possible influence of occlusion movement on the secretion of parotid saliva by means of the same suction-cup for parotid gland purpose.

\section{Experimental Technique}

For the measurement of parotid salivary secretion use has been made of HAYASHISUHARA parotid salivary suction-cup. The same instrument was attached onto the open portion of the parotid gland on buccal mucous membrane of a person subjected to the experiment through negative pressure. Parotid saliva which subsequently secreted was induced into the manometer and measured in terms of $\mathrm{mm}$. Persons who were subjected to the experiment included both sexes of normal health with age range from 16 to 45 years of age.

As for the experimental process, in the first place the amount of resting saliva for a specified length of time was measured from the examinees. Then, as the second step, the examinees were requested to carry on the occlusion movement moving their jaws for a given period of time. The amount of saliva thus secreted was measured and was compared with that of the first step. In the final step, the examinees were asked to chew on paraffin wax and chewing-gum as saliva stimulants and the amount of saliva thus induced was measured again for the comparative purpose.

\section{Experimental Data}

\section{Measurement of saliva in empty occlusion movement.}

As the second step of the experiment process described in the foregoing section, the examinees were instructed to carry on the occlusion movement without anything inserted in their mouth, the frequency of their movement being from 90 to 110 times per minute. This movement was designated as 'An empty occlusion movement' to refer

* 栖原六郎, 小野 清, 滝川富雄, 田中政雄: Dept. of Physiology, Nihon Univ. School of Dentistry (Director: Prof. Rokuro SUHARA). 
to this process. The empty occlusion movement was continued for a length of 9 minutes for the measurement at a time. Table 1 gives a comparison between the amount of normally secreted parotid saliva and that of the same saliva induced by the empty occlusion movement.

TABLE 1

Parotid Saliva Induced by the Empty Occlusion Movement (in Terms of $\mathrm{mm}$ for 3 Minutes)

\begin{tabular}{c|c|c|c|c}
\hline No. & Sex & Age & Amount of resting saliva & $\begin{array}{c}\text { Amount of parotid } \\
\text { saliva induced }\end{array}$ \\
\hline 1 & + & 22 & $3 \mathrm{~mm}$ & $6 \mathrm{~mm}$ \\
2 & 0 & 25 & 21 \\
3 & $\hat{0}$ & 21 & 32 & 26 \\
4 & $\hat{0}$ & 37 & 28 \\
5 & $\hat{0}$ & 21 & 38 & 27 \\
6 & $\hat{0}$ & 20 & 43 & 34 \\
& $\hat{0}$ & 16 & &
\end{tabular}

A conclusion to be derived from the Table seems to be that the amount of parotid saliva induced by the empty occlusion movement is parallel to that of normal resting saliva and, in some cases, it is somewhat less than the latter.

2. Measurement of saliva in occlusion movement with paraffin wax.

A piece of solid paraffin wax (5g.) was inserted in the mouth of an examinee and he was instructed to carry on the occlusion movement as long as 9 minutes. The amount of parotid saliva that was induced as a consequence was measured and compared against that of resting saliva in normal conditions. Reference is made to Table 2. No special instructions were issued to the examinees as to the manner of moving their jaws but the frequency of their movement was in the range of 80 to 100 times per minute.

As is known from Table 2, the amount of parotid saliva induced by the insertion of paraffin was is about anywhere from 1.2 to 33.1 times as much as that of resting saliva under normal circumstances (the average being 7.5 times). The empty occlusion movement referred to in the foregoing section (Table 1) does not bring about any secretion of reflex saliva, whereas in the present test a certain amount of reflex saliva has

TABLE 2

Parotid Saliva Induced by Insertion of Paraffin Wax in the Mouth (in terms of $\mathrm{mm}$ for 3 minutes)

\begin{tabular}{|c|c|c|c|c|}
\hline No. & Sex. & Age & Amount of resting saliva & $\begin{array}{l}\text { Amount of parotid saliva } \\
\text { induced by paraffin wax }\end{array}$ \\
\hline 1 & $\hat{o}$ & 22 & $8 \mathrm{~mm}$ & $278 \mathrm{~mm}$ \\
\hline 2 & 우 & 19 & 14 & 34 \\
\hline 3 & 우 & 41 & 15 & 18 \\
\hline 4 & $\hat{\delta}$ & 21 & 19 & 122 \\
\hline 5 & $\hat{o}$ & 45 & 43 & 115 \\
\hline 6 & $\hat{o}$ & 20 & 48 & 142 \\
\hline
\end{tabular}


secreted supposedly due to peculiar taste and smell of paraffin was that stimulated the gustatory organ and others.

\section{Measurement of saliva in occlusion movement with chewing-gum.}

Following the measurement of resting saliva collected for a length of 15 minutes (the average being struck on 3 minutes in terms of $\mathrm{mm}$.), an ordinary commercial chewing-gum was used as salivary stimulant. A fresh piece of $5 \mathrm{~g}$. was used on the daily basis. The amount of parotid saliva induced by the occlusion movement with this chewing-gum, each 3 minutes for three times in succession with the chewing frequency from 80 to 110 times, was measured and contrasted aganist the former. See Table 3. From Table 3, we find that a comparison between the amount of normal resting saliva and that of parotid saliva thus induced by this process indicates the latter is anywhere from 11.4 to 116.4 times as much as that of the former (the average being 45.2 times). It is obvious that a fine flavor and taste of chewing-gum constitute a prime factor in stimulating reflex saliva.

TABLE 3

Measurement of Salivary Secretion with Chewing-gum (in terms of $\mathrm{mm}$ for minutes)

\begin{tabular}{c|c|c|c|c}
\hline No. & Sex & Age & Amount of resting saliva & $\begin{array}{c}\text { Salivary secretion } \\
\text { induced by chewing-gum }\end{array}$ \\
\hline 1 & $\hat{0}$ & 21 & 8 & 455 \\
2 & $\hat{\delta}$ & 20 & 8 & 908 \\
3 & $\hat{0}$ & 21 & 27 & 384 \\
4 & $\hat{0}$ & 21 & 42 & 309 \\
5 & $\hat{\delta}$ & 16 & & 893
\end{tabular}

4. Measurement of saliva in occlusion movement with tasteless chewing-gum.

a) A piece of chewing-gum (5g.) was inserted in the mouth and the occlusion movement took place for 9 minutes successively, the chewing frequency ranging from 80 to 110 times. The average value of 3 minutes is given in Table $4(A)$ which compares with the amount of resting saliva under normal conditions. These two sets of figures indicate that the stimulated salivary secretion is anywhere from 2.0 to 18.3 times with the average value about 6.9 times.

b) 5 gram piece of acetic vinyl $\left(\mathrm{CH}_{2}=\mathrm{CHOCOH}_{2}\right)$ a kind of synthetic resin used as raw material for the manufacturing of chewing-gum was also inserted in the mouth,

TABLE $4(A)$

\begin{tabular}{|c|c|c|c|c|}
\hline No. & Sex & Age & Amount of resting saliva & $\begin{array}{l}\text { Salivary secretion } \\
\text { induced by tasteless gum }\end{array}$ \\
\hline 1 & $\hat{\delta}$ & 21 & 8 & 36 \\
\hline 2 & $\hat{o}$ & 20 & 8 & 143 \\
\hline 3 & s & 21 & 19 & 123 \\
\hline 4 & $\hat{o}$ & 21 & 27 & 88 \\
\hline 5 & $\hat{o}$ & 20 & 48 & 97 \\
\hline
\end{tabular}


and a similar occlusion movement was repeated as in the previous manner. The figures thus obtained are given in Table $4(B)$ as follows.

TABLE $4(B)$

\begin{tabular}{|c|c|c|c|c|}
\hline No. & Sex & Age & Amount of resting saliva & $\begin{array}{c}\text { Salivary secretion } \\
\text { induced by acetic vinyl }\end{array}$ \\
\hline 1 & 우 & 22 & 2 & 327 \\
\hline 2 & $\hat{o}$ & 22 & 2 & 765 \\
\hline 3 & $\hat{o}$ & 22 & 4 & 253 \\
\hline 4 & $\hat{s}$ & 21 & 22 & 35 \\
\hline
\end{tabular}

\section{Considerations and Summary}

In the present experiment efforts have been made by the authors to determine possible influence which the occlusion movement exercises on the secretion of parotid saliva in the Japanese.

The following findings are obtained as a result of a series of tests described in the foregoing sections :

1) No increase in the salivary secretion has been observed in the case of the empty occlusion movement where nothing is inserted in the mouth as contrasted against the salivary secretion under normal circumstances. On the contrary, a decrease is observed in some cases. It may be attributed to the fact that when the empty occlusion movement is repeated for a certain length of time, it does not bring about any reflex secretion but rather works as inhibitory factor upon the normal secretion.

2) Although paraffin wax is accompanied with a certain unpleasant taste, it evidently stimulates the secretion of reflex saliva. The amount of parotid saliva that was induced as a consequence is about 7.5 times as much as the case of normal secretion.

3) When a piece of chewing-gum is inserted in the mouth for a length of time, there is seen a far greater increase in the salivary secretion than the case of 2) above. The average increase amounts to 45.2 times as much as the normal secretion. This phenomenon more or less parallels to a set of findings which were obtained by the present authors (SUHARA and ASAKAWA ${ }^{4}$ ) as a result of tests in which lunch and other foods were provided to the examinees.

4) Insertion of a tasteless chewing-gum also increases the salivary secretion by about 6.9 times on the average. Infusion of acetic vinyl in the mouth is known to give rise to a similar increase.

The conclusion to be drawn from these series of tests indicates the insertion of various substances in the oral cavity and the occlusion movement thereof brings about an increase in the salivary secretion, whereas the mere occlusion movement without anything in the oral cavity is not accompanied by an increase worthy of note.

\section{Reference}

1) Hayashi, T. : Conditioned Reflex (Jap.), Sanseido, Tokyo, 1937. Methodology of Conditioned Reflex (Jap.), Nakayama-shoten, Tokyo, 1950.

2) Hayakawa, R. : Study on Parotid Resting Saliva of Man, 'Conditioned Reflex's', (Jap.), XIII, 1948. 
3) Suhara, R. : Study on the Amount of Human Saliva in Parotid Gland (Eng.), Dent. J. Nihon Univ., Vol. 1, No. 1, 1958.

4) Suhara, R. and Asakawa, H. : : On the Composition of Human Parotid Resting Saliva and Reflex Saliva (Eng.), Journ. of Nihon Univ. Sch. of Dent., Vol. 1, No. 3, 1959.

5) Suhara, R. et al. : Comparative Study on Quantities of Submaxillar, Sublingual and Parotid Salivas in Man (Eng.), Journ. of Nihon Univ. Sch. of Dent., Vol. 1, No. 4, 1959. 